\title{
Rigid-Rod Polyesters with Flexible Side Chains Based on 1,4-Dialkylesters of Pyromellitic Acid II. Mesogenic Properties of $\mathrm{H}-\mathrm{Cn}$ Polyesters Prepared from 1,4-Dialkylesters of Pyromellitic Acid and Hydroquinone
}

\author{
Junji Watanabe, Brian R. Harkness, and Masato Sone \\ Department of Polymer Chemistry, Tokyo Institute of Technology, \\ Ookayama, Meguro-ku, Tokyo 152, Japan
}

(Received April 21, 1992)

\begin{abstract}
Rigid-rod polyesters with long alkyl side chains, denoted as $\mathrm{H}-\mathrm{C} n$, have been prepared by reacting 1,4-dialkylesters of pyromellitic acid with hydroquinone. The alkyl groups were varied from hexyl $(n=6)$ to octadecyl $(n=18)$. The mesomorphic properties and structure of these polyesters were examined by optical microscopy, DSC and X-ray measurements. The experimental results indicate that the $\mathrm{H}-\mathrm{C} n$ polyesters with side-chain lengths of $n \geqq 12$ exhibit liquid crystalline mesophases with a characteristic layered structure. In this structure, the aromatic main chains in the extended form pack into layers with one-dimensionally positional order in the lateral direction and the alkyl side chains in the disordered form occupy the space between the layers. This layered structure is considered to result from a kind of microphase separation of the aromatic and aliphatic components of the polymer, which results in an unusually observed increase in the isotropization temperatures of liquid crystals with an increase in the side-chain length.

KEY WORDS Aromatic Polyester / Liquid Crystal / Layered Structure /

Pyromellitic Acid / Alkyl Side Chain /
\end{abstract}

The study of liquid crystalline polyesters has received considerable attention because of the industrial importance of these considerable attention because of the industrial importance of these materials and their ability to form different types of liquid crystalline phases. ${ }^{1}$ Polyesters have been shown to form nematic, cholesteric and smectic liquid crystals. More recently it has been reported that rigid-rod polyesters with long alkyl side chains form novel layered structures that exhibit mesomorphic properties. ${ }^{2-10}$ These layered structures are characterized by a lateral packing of the polymer main chains into layers that propagate in a direction perpendicular to the main-chain axis. The disordered side chains occupying between the layers guarantee the liquid crystalline nature for these layered phases.

In the first paper of this series, ${ }^{10}$ we prepared the rigid-rod polyesters with the similar structural feature based on the 1,4-ditetradecylester of pyromellitic acid. Here, the dialkylester monomer was easily prepared by reacting pyromellitic dianhydride with tetradecanol and purifying the para-isomer by washing the reaction mixture with acetone followed by methylene chloride. Conversion of this product to the acid chloride followed by condensation with hydroquinone or 4,4'biphenol yielded the polyesters $\mathrm{H}-\mathrm{C} 14$ or B-C14 with the following formula, respectively; 


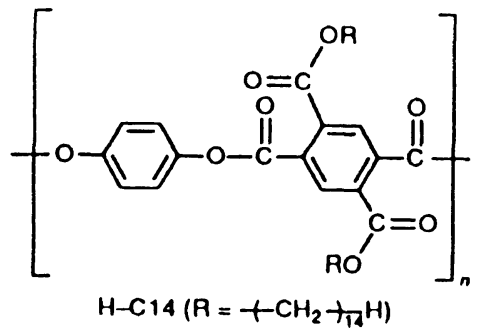

The $\mathrm{H}-\mathrm{C} 14$ polyester was observed to form a highly ordered liquid crystalline phase with a layered structure ${ }^{10}$ similar to those reported by other researchers. ${ }^{4,6-9}$ The B-C14 polyester, on the other hand, formed two types of liquid crystalline layered structures depending on the temperature of the mesophase. Both of these structures were suggested to be different from the layered structure of the $\mathrm{H}-\mathrm{C} 14$ mesophase with respect to the packing order of molecules within a layer and/or between the layers. ${ }^{10}$

To examine in further detail the structural property of the layered mesophase, in this study we prepared a homologous series of polyesters based on hydroquinone and 1,4-dialkylesters of pyromellitic acid, in which the alkyl sidechain length is varied from 6 to 18 carbon atoms. These polymers shall be referred to as $\mathrm{H}-\mathrm{Cn}$ where $n$ denotes the number of carbon atoms in the $n$-alkyl side chain. The mesophase behavior and structure will be analyzed by DSC, optical microscopic and X-ray methods, and discussed in a relation to the alkyl side-chain length.

\section{EXPERIMENTAL}

\section{Materials}

Tetrahydrofuran (THF) and toluene were distilled from $\mathrm{LiAlH}_{4}$ prior to use. Triethylamine was distilled from $\mathrm{NaH}$. Pyromellitic diahydride $(1,2,4,5$-benzenetetracarboxylic dianhydride), $n$-alcohols and hydroquinone from Tokyo Chemical were used without further purification.

\section{Methods}

${ }^{1} \mathrm{H}$ NMR spectra were obtained with a JEOL

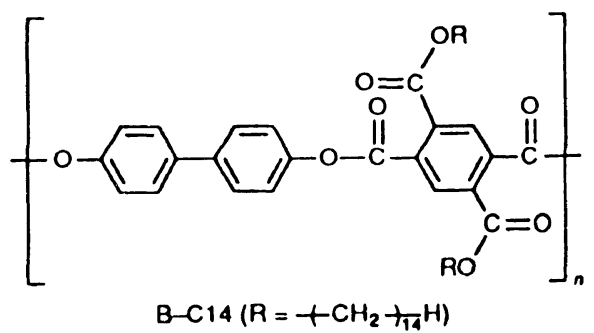

FX90Q spectrometer at a frequency of $90 \mathrm{MHz}$. DSC measurements were performed with a Perkin-Elmer DSC-II calorimeter at a scanning rate of $10^{\circ} \mathrm{C} \mathrm{min}^{-1}$. Wide-angle X-ray diffraction patterns of the polymers were recorded with a flat-plate camera mounted in a Rigaku-Denki X-ray generator emitting $\mathrm{Ni}$-filtered $\mathrm{Cu}-K_{\alpha}$ radiation. The temperature of the samples was controlled by placing the samples in a Mettler FP- 80 hotstage mounted in the beampath. The film to specimen distance was determined by callibration with silicon powder. Optical microscopic observations of the liquid crystalline textures were made with an Olympus $\mathrm{BH}-2$ polarizing microscope equipped with a Mettler FP-80 hotstage.

\section{RESULTS AND DISCUSSION}

\section{Synthesis of $\mathrm{H}-\mathrm{Cn}$ Polyesters}

As discussed in a previous report, ${ }^{10}$ the 1,4-di- $n$-alkylester of pyromellitic acid can be prepared and purified according to the route outlined in Chart I.

The separation of the meta- and para-isomers is achieved by taking advantage of the much greater solubility of the meta-isomer in organic solvents. In the case of the di- $n$-tetradecylester, a simple washing of the mixture with acetone results in the dissolution of the meta-isomer leaving the insoluble para-isomer that can be isolated by filtration. ${ }^{10}$ This general procedure has been used to generate a series of 1,4-di- $n$-alkylesters of pyromellitic acid in which the alkyl moiety ranges from hexyl(C6) to octadecyl(C18). In order to accommodate the differing solubility of the meta-isomer with 
Polyesters with Side Chains II.

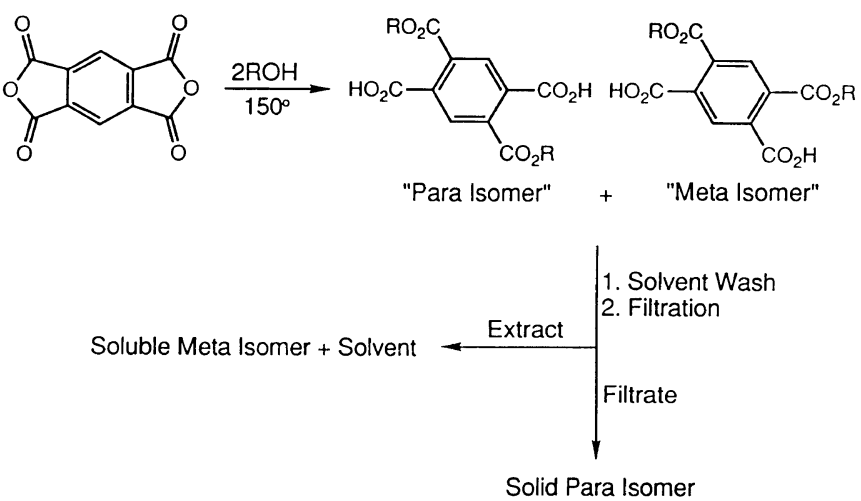

Chart I.

Table I. Purification solvent, melting temperature, and yields of 1,4-dialkylesters of pyromellitic acid

\begin{tabular}{|c|c|c|c|}
\hline \multirow{2}{*}{$\begin{array}{l}\text { 1,4-Dialkylesters of } \\
\text { pyromellitic acid }\end{array}$} & Melting point & \multirow{2}{*}{$\begin{array}{c}\text { Monomer washing } \\
\text { solvent }\end{array}$} & \multirow{2}{*}{$\frac{\text { Yield }}{\%}$} \\
\hline & ${ }^{\circ} \mathrm{C}$ & & \\
\hline C6 & $153-155$ & Crystallized from toluene ${ }^{a}$ & 34 \\
\hline $\mathrm{C} 8$ & $150-153$ & $\mathrm{CH}_{2} \mathrm{Cl}_{2}$ & 38 \\
\hline $\mathrm{C} 10$ & $150-154$ & $\mathrm{CH}_{2} \mathrm{Cl}_{2}$ & 37 \\
\hline $\mathrm{C} 12$ & $151-155$ & $\mathrm{CH}_{2} \mathrm{Cl}_{2}$ & 44 \\
\hline $\mathrm{C} 14$ & $151-155$ & Acetone $/ \mathrm{CH}_{2} \mathrm{Cl}_{2}{ }^{\mathrm{b}}$ & 35 \\
\hline $\mathrm{Cl} 6$ & $153-154$ & Acetone $/ \mathrm{CHCl}_{3}{ }^{\mathrm{b}}$ & 46 \\
\hline $\mathrm{C} 18$ & $151-153$ & Acetone $/ \mathrm{CHCl}_{3}{ }^{\mathrm{b}}$ & 47 \\
\hline
\end{tabular}

a Refer to the comment in the text.

${ }^{b}$ In these cases acetone was sufficient to purity the para isomer from the meta isomer however a second washing was performed to remove residual alcohol.

varying side-chain lengths, the washing solvent had to be varied slightly throughout the series. The washing solvents utilized and the monomer melting points and yields are recorded in Table I. For the hexylesters of pyromellitic acid the para-isomer was further purified by recrystallization from toluene.

To generate the hydroquinone polyesters (abbreviated as $\mathrm{H}-\mathrm{C} n$ where $n$ denotes the number of carbon atoms in the alkyl side chain), the para-dialkylesters were converted to their respective acid chlorides and then reacted with hydroquinone as presented in a previous report. ${ }^{10}$ The para-isomer monomers and their respective polymers have been characterized by ${ }^{1} \mathrm{H}$ NMR spectroscopy. ${ }^{10}$

The inherent viscosities of the $\mathrm{H}-\mathrm{Cn}$
Table II. Inherent viscosities and transition temperatures for the $\mathrm{H}-\mathrm{C} n$ polyesters ${ }^{c}$

\begin{tabular}{lcccc}
\hline Polymer & $\eta_{\text {inh }}: \mathrm{dlg}^{-1}$ & $T_{1} /{ }^{\circ} \mathrm{C}$ & $T_{2} /{ }^{\circ} \mathrm{C}$ & $T_{\mathrm{i}} /{ }^{\circ} \mathrm{C}$ \\
\hline $\mathrm{H}-\mathrm{C} 6$ & 0.28 & - & - & 132 \\
$\mathrm{H}-\mathrm{C} 8$ & 0.38 & - & - & 124 \\
$\mathrm{H}-\mathrm{C} 10$ & 0.39 & - & - & 103 \\
$\mathrm{H}-\mathrm{C} 12$ & 0.57 & - & 99 & 128 \\
$\mathrm{H}-\mathrm{C} 14$ & 0.23 & 45 & 94 & 149 \\
$\mathrm{H}-\mathrm{C} 16$ & 0.31 & 43 & 101 & 146 \\
$\mathrm{H}-\mathrm{C} 18$ & 0.26 & 44 & 111 & 124
\end{tabular}

a Transition temperatures were recorded for the first heating DSC scans of the THF-cast films.

polyesters, $\eta_{\text {inh }}$, were measured in THF at $25^{\circ} \mathrm{C}$ and are listed in the second column of Table II. All of the $\mathrm{H}-\mathrm{C} n$ polyesters prepared for this study have been found to form isotropic melts 
in the temperature region of $100^{\circ} \mathrm{C}$ to $150^{\circ} \mathrm{C}$. In addition, these materials are quite soluble in solvents such as THF and chloroform and can be cast into fine films. In a previous paper, ${ }^{10}$ the thermotropic behavior was examined for a melt pressed film of $\mathrm{H}-\mathrm{C} 14$, but in this study all of the specimens have been prepared as films cast from THF solutions, so as to promote the crystallization of the polymers.

\section{Typical Phase Behavior Observed for the $\mathrm{H}-\mathrm{Cl}$} Polyester

The DSC heating thermograms of THF-cast films are shown in Figure 1. As a typical example, the DSC scan of the $\mathrm{H}-\mathrm{C} 16$ film in Figure $1 \mathrm{~b}$ shows a small transition around $43^{\circ} \mathrm{C}$ and a large transition with a maximum at $101{ }^{\circ} \mathrm{C}$. This second transition can be attributed to the melting of polymer crystallites that consist of a combination of side-chain crystals and main-chain crystals as will be discussed later. The enthalpy of this transition is approximately $7.7 \mathrm{kcal}$ (mol of repeat unit) $)^{-1}$. A liquid crystalline phase is observed following the melting of the crystallites as indicated by the high birefringence and ability of flow. Continued heating results in another small transition $\left(\Delta H=1.0 \mathrm{kcal} \mathrm{mol}^{-1}\right)$ at $146^{\circ} \mathrm{C}$ that can be attributed to the liquid crystal to isotropic phase transition as verified by the loss of the birefringence at this temperature. The $\mathrm{H}-\mathrm{C} 16$ cast film, thus, shows three transitions which are denoted as $T_{1}, T_{2}$, and $T_{\mathrm{i}}$ in order of increasing temperature.

$\mathrm{X}$-Ray difiraction studies were performed on the crystalline and liquid crystalline phases of $\mathrm{H}-\mathrm{C} 16$. Figure 2a shows the $\mathrm{X}$-ray diffraction pattern for an as-cast film of $\mathrm{H}-\mathrm{C} 16$ as measured at room temperature with the beam parallel to the film surface. The spacings of the observed reflections are summarized in the first column of Table III. Obviously, this pattern includes many reflections and is characteristic of a crystalline structure although at this stage the detailed structure can not be determined.

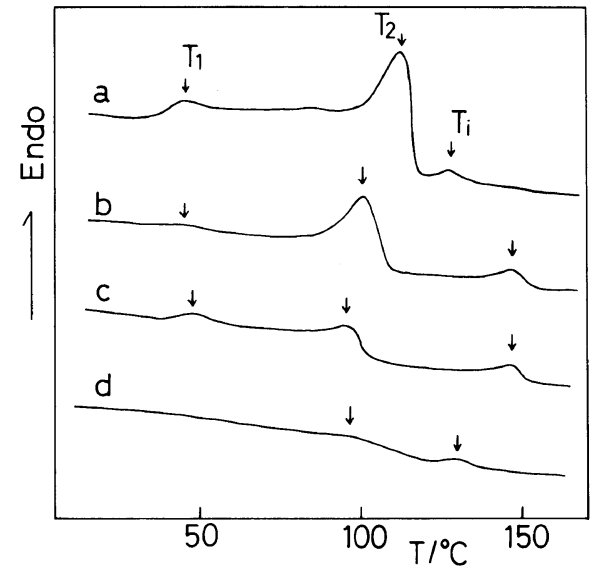

Figure 1. The DSC heating thermograms of the THF-cast films: (a) $\mathrm{H}-\mathrm{Cl}$; (b) $\mathrm{H}-\mathrm{Cl}$; (c) $\mathrm{H}-\mathrm{Cl} 4$; (d) $\mathrm{H}-\mathrm{C} 12$.

As one of its characteristics, the crystalline phase includes side-chain crystallites as indicated by the strong $4.12-\AA$ reflection. ${ }^{11}$ Several other reflections likely result from the crystal packing of the aromatic main chains. Hence, the crystalline phase consists of a combination of side-chain crystals and mainchain crystals. ${ }^{12}$ On heating the film to a temperature above the $T_{1}$ transition, the crystal diffraction pattern is essentially unchanged, suggesting that the small $T_{1}$ transition may be attributed to the melting of localized side-chain crystallites. In fact, this small transition disappears when the film is annealed at temperatures between the $T_{1}$ and $T_{2}$ transitions. Continued heating to a temperature above the $T_{2}$ transition results in the loss of the crystal diffraction pattern and the appearance of a pattern characteristic of the liquid crystalline phase (see Figure $2 \mathrm{~b}$ and the second column of Table III). The detailed structure of liquid crystalline phase shall be presented later.

\section{General Phase Behavior of the $\mathrm{H}-\mathrm{Cn}$ Polyesters}

From the DSC thermograms of Figure 1, it is apparent that the $\mathrm{H}-\mathrm{C} 12, \mathrm{H}-\mathrm{C} 14$, and $\mathrm{H}-\mathrm{C} 18$ cast films exhibit similar transition behavior to that observed for the $\mathrm{H}-\mathrm{C} 16$ film, 


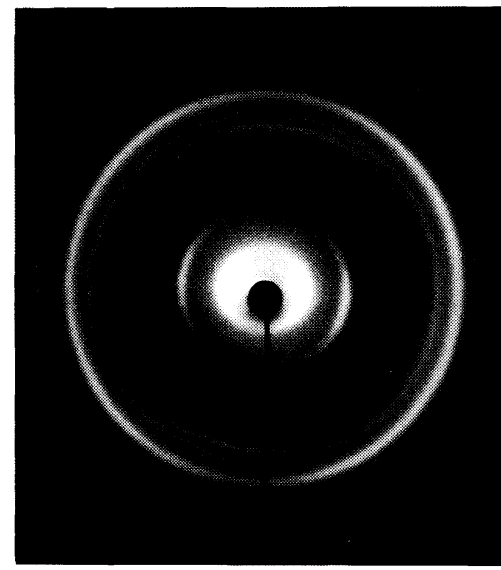

(a)

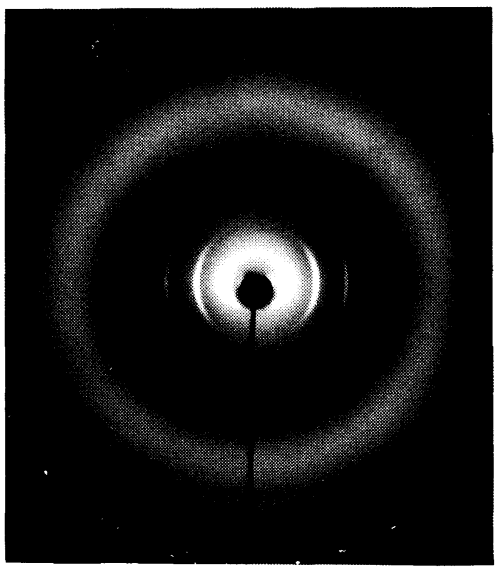

(b)

Figure 2. X-Ray photographs of the as-cast film of $\mathrm{H}-\mathrm{C} 16$ : (1) the crystalline phase at $25^{\circ} \mathrm{C}$; (b) the liquid crystalline phase at $120^{\circ} \mathrm{C}$. Here, the $\mathrm{X}$-ray photographs were taken with the beam parallel to the film surface.

Table III. X-Ray data for the crystalline and liquid crystalline phases observed for $\mathrm{H}-\mathrm{C} 16$ cast film

\begin{tabular}{cc}
$\begin{array}{c}\text { Crystalline phase } \\
\left(\text { at } 25^{\circ} \mathrm{C}\right),\end{array}$ & $\begin{array}{c}\text { Liquid crystalline phase } \\
\left(\text { at } 120^{\circ} \mathrm{C}\right), \\
d / \AA\end{array}$ \\
\hline $18.8 \mathrm{vs}^{\mathrm{a}}$ & $26.6 \mathrm{vs}$ \\
$9.29 \mathrm{~s}$ & $13.3 \mathrm{~s}$ \\
$7.87 \mathrm{vvw}$ & $8.87 \mathrm{~m}$ \\
$6.75 \mathrm{w}$ & $6.65 \mathrm{w}$ \\
$6.10 \mathrm{vvw}$ & $5.32 \mathrm{vw}$ \\
$5.35 \mathrm{vvw}$ & \\
$4.89 \mathrm{~m}$ & \\
$4.58 \mathrm{w}$ & \\
$4.12 \mathrm{~s}$ & \\
$3.83 \mathrm{vw}$ & \\
$3.59 \mathrm{w}$ & $3.85 \mathrm{~m}$ \\
\hline
\end{tabular}

a vs, very strong; s, strong; m, medium; w, weak; vw, very weak; vvw, very very weak.

with the exception that the degree of crystallinity of the crystalline phase decreases with a decrease in the length of alkyl side chains. This is evident from the observation that the enthalpies for the $T_{2}$ transition peaks are $12.7,7.7,5.0$ and $1.0 \mathrm{kcal} \mathrm{mol}^{-1}$ for $\mathrm{H}-\mathrm{Cl}$, $\mathrm{H}-\mathrm{C} 16, \mathrm{H}-\mathrm{C} 14$, and $\mathrm{H}-\mathrm{C} 12$, respectively, while the enthalpy of the liquid crystal to isotropic phase transition is almost the same for all specimens, about $1 \mathrm{kcal} \mathrm{mol}^{-1}$. A further reduction in the length of side chain results in DSC thermograms of the $\mathrm{H}-\mathrm{C} 10, \mathrm{H}-\mathrm{C} 8$, and $\mathrm{H}-\mathrm{C} 6$ polyester films exhibiting a direct transition from the crystal to isotropic phase and no liquid crystalline phase. The transition temperatures are summarized in Table II.

The transition temperatures (open circles) based on the DSC data are plotted as a function of $n$ in Figure 3. The $T_{\mathrm{i}}$ temperatures (closed circles) determined from the optical microscopy are also included in the same Figure. From these results, it is obvious that the liquid crystalline phase appears for $\mathrm{H}-\mathrm{C} n$ polyesters in which $n$ is 12 or longer. An interesting aspect of this transition behavior is the trend where the isotropization temperature of the crystalline phase, $T_{\mathrm{i}}$, initially decreases as $n$ increases from 6 to 10 , but $T_{\mathrm{i}}$ for the liquid crystal increases with a further increase of $n$, exhibiting a maximum for $\mathrm{H}-\mathrm{C} 14$. This indicates that the liquid crystalline phase arises not only as the result of a decrease in the crystal melting temperatures but also by an increase of the $T_{\mathrm{i}}$ 


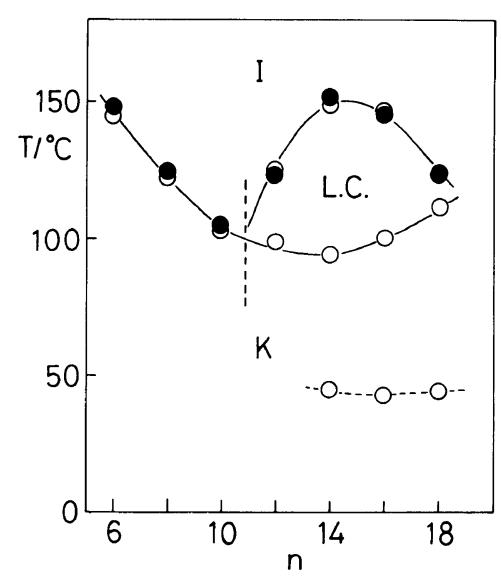

Figure 3. Variation of transition temperatures with the number of carbon atoms in the alkyl side chain, $n$. The open circles are based on the heating DSC scan and the closed circles based on the optical microscopy.

temperatures for the liquid crystalline phases. A similar trend has also been observed for thermotropic alkyl-ester derivatives of cellulose $^{13}$ which exhibit a columnar hexagonal phase when the alkyl side chain is longer than an octyl group. In the columnar phase, the individual column can be viewed as a type of micellar structure that results from differences in the polarity and/or geometric shape of the cellulosic main chain and aliphatic side chain. In the case of the $\mathrm{H}-\mathrm{Cn}$ polyesters, hence, we can speculate that the stability of the liquid crystalline phases may result from a type of microphase separation of the two components, the aromatic main chain and the aliphatic side chain, which occurs most readily for longer side chains. An alternative explanation for the trend in $T_{\mathrm{i}}$ may be variations in the molecular weights of the polymers, however the viscosity data does not support this possibility (refer to the second column of Table II).

\section{The Mesophase Structure of the H-Cn Poly- esters}

The X-ray pattern of the liquid crystalline phase is very simple and oriented patterns can be obtained for both as-cast films and melt-spun fibers. The X-ray photograph of the liquid crystalline phase (Figure $2 b$ ), as observed for $\mathrm{H}-\mathrm{C} 16$ film at $120^{\circ} \mathrm{C}$, includes a series of sharp equatorial h00 reflections with spacings of $26.6,13.3,8.87$, and $6.65 \AA$. Two other wide-angle reflections are observed. The first with a spacing of approximately $4.6 \AA$ appears as a diffuse halo and the second appears as a sharp reflection with a spacing of $3.85 \AA$, showing stronger intensity on the meridional line. The X-ray study was also performed on oriented fibers spun from the isotropic melt. In this case as presented in a previous paper, ${ }^{10}$ both of h00 reflections and $3.85-\AA$ reflection appear on the equatorial line perpendicular to the fiver axis. A diffuse halo with a spacing of approximately $4.6 \AA$ appears with relatively stronger intensity of the equatorial line. Futhermore, weak meridional streaks with spacings of $12 \AA$ and $6 \AA$ also appear which cannot be recognized in the as-cast film.

Similar X-ray patterns were observed for the liquid crystalline phases of the polyesters, $\mathrm{H}-\mathrm{C} 12, \mathrm{H}-\mathrm{C} 14$, and $\mathrm{H}-\mathrm{C} 18$. The only difference between them are the observed spacings for the h00 reflection, which increase linearly with an increase in $n$. All other reflections appear to have the same spacings and the same angular displacement in both film and fiber specimens. The X-ray data are listed in Table IV and are presented in Figure 4 where the spacings of the 100 reflection are plotted as a function of $n$.

These X-ray data are indicative of a layered structure for the liquid crystalline phase of the $\mathrm{H}-\mathrm{Cn}$ polyesters, as illustrated in Figure 5a. Here, the observed reflections in the series h00 can be attributed to a layered structure that is formed with a layer plane parallel to the film surface in the cast film (Figure 5b) or parallel to the fiber axis in the fiber specimen (Figure $5 c$ ). Each layer is formed by a regular lateral packing of the aromatic main chains, as can be elucidated from the sharp reflection at $3.85 \AA$. A different angular displacement of this reflection relative to the $h 00$ reflections has been observed between the film and fiber specimens, 
Table IV. X-Ray data of the liquid crystalline phase $^{\mathrm{a}}$

\begin{tabular}{ccccc}
\hline & $\mathrm{H}-\mathrm{Cl} 2$ & $\mathrm{H}-\mathrm{Cl} 4$ & $\mathrm{H}-\mathrm{C} 16$ & $\mathrm{H}-\mathrm{C} 18$ \\
\hline$d_{100} / \AA$ & 22.3 & 24.3 & 26.6 & 29.0 \\
$d_{200} / \AA$ & 11.1 & 12.2 & 13.3 & 14.5 \\
$d_{300} / \AA$ & & 8.13 & 8.87 & 9.72 \\
$d_{400} / \AA$ & & 6.07 & 6.65 & 7.28 \\
$d_{500} / \AA$ & & 4.86 & 5.32 & \\
$d_{010} / \AA$ & 3.86 & 3.85 & 3.85 & 3.85 \\
\hline
\end{tabular}

a X-Ray data were recorded for the liquid crystalline phases at $110^{\circ} \mathrm{C}$.

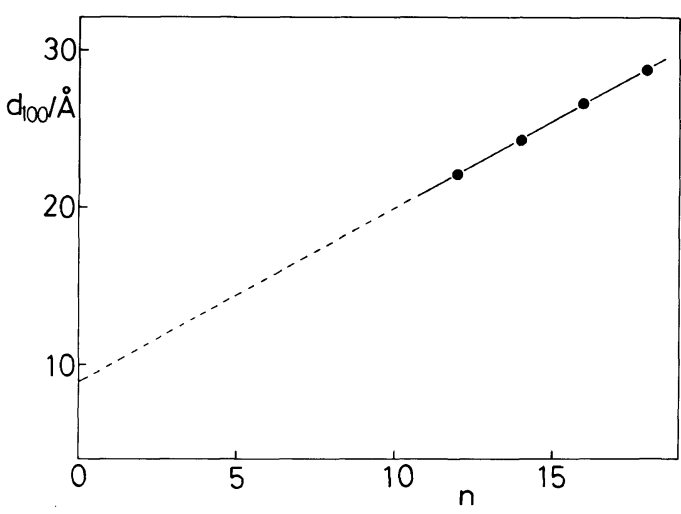

Figure 4. Plot of spacings of the 100 reflection in the liquid crystalline phase $v s$. the carbon number of the alkyl side chain, $n$.

but this can be explained by the different orientation of the layers; in the film specimen the layers lie in a plane parallel to the film surface but with a random orientation of the layer axis (corresponding to the chain axis) while in the fiber specimen both the layer plane and layer axis lie parallel to the fiber axis. The main chain is in an extended conformation since the spacing of the meridional reflection, $12 \AA$, as observed in the fiver specimen, is in agreement with the value calculated by Erman et al. ${ }^{14}$ for a polyester with the same main-chain repeat unit. The appearance of this reflection as a weak streak indicates a random displacement of main chains along the chain axis within a layer as in a nematic liquid crystal.
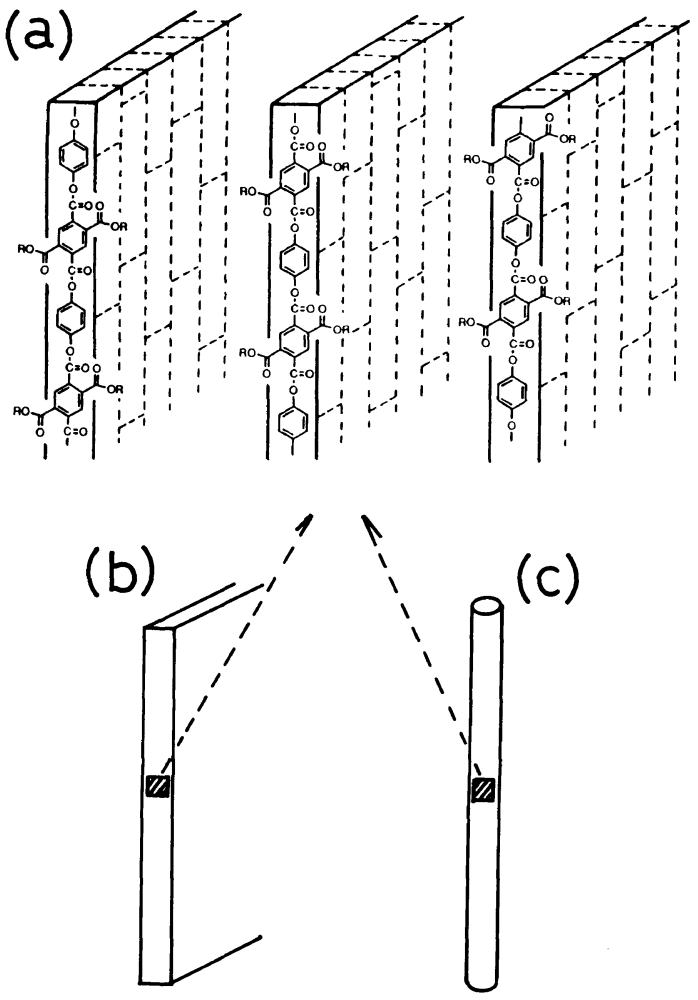

Figure 5. (a) A proposed layered structure for the liquid crystalline phase. In this layered structure, the aromatic main chains in the extended form pack into layers with positional order only in the lateral direction, and the aliphatic side chains in the disordered form occupy the space between layers. In the cast films, the layers lie parallel to the film surface but with a random arrangement of the layer axis (b), while in as-spun fibers both the layer plane and layer axis lie parallel to the fiber axis (c).

The diffuse halo with a spacing of $4.6 \AA$ can be attributed to the disordered alkyl side chains that occupy the space between the layers. Judging from the layer spacings, the side chains sticking out of the neighboring layers interpenetrate into each other. ${ }^{11}$ The calculated densities based on this model are 1.08, 1.07, 1.05 , and $1.05 \mathrm{~g} \mathrm{ml}^{-1}$ for $\mathrm{H}-\mathrm{C} 12, \mathrm{H}-\mathrm{C} 14$, $\mathrm{H}-\mathrm{C} 16$, and $\mathrm{H}-\mathrm{C} 18$, respectively, which can be expected for these types of liquid crystals.

An examination of the sample density allows for further illustration of this layered structure. Returning to Figure 4, it is evident that there 
(a)
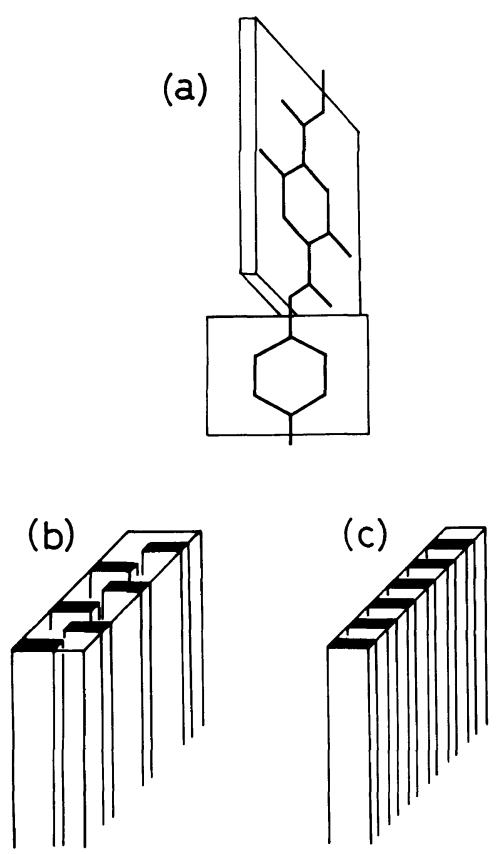

Figure 6. A schematic illustration of (a) the most stable conformation of the aromatic main chain. The space filling requires the aromatic main chain in this conformation to pack in a zig-zag fashion (b) rather than in a side-by-side fashion (c) within a layer (see the text).

is a linear relationship between the layer spacing and the number of carbon atoms in the alkyl side chains. The slope gives an averaged increment of $1.12 \AA$ per unit of $n$. The volume per two methylene $\left(\mathrm{CH}_{2}\right)$ units can therefore be given by $1.12 \AA \times 3.85 \AA \times 12.0 \AA$ where the second and third factors are the distance between the main chains within a layer and the repeat length of the main chain, respectively. Thus, the density per $\mathrm{CH}_{2}$ unit is calculated to be $0.90 \mathrm{~g} \mathrm{~cm}^{-1}$ which is somewhat larger than that $\left(0.85 \mathrm{~g} \mathrm{~cm}^{-1}\right)$ of the amorphous phase of polyethylene. ${ }^{9}$ On the other hand, extrapolation of the layer spacing to $n=0$ gives $9 \AA$, leading to a density of 1.30 $\mathrm{g} \mathrm{ml}^{-1}$ for the domain composed of the aromatic main chains without alkyl substituents. These elucidated densities likely include some error, but are enough to envisage that there is a remarkable difference in density between the main-chain and side-chain domains.

Finally it should be noted that the detailed packing structure of main chains within the individual layer is still unknown. Two possible packing structures can be proposed in a relation to the chain conformation. As determined experimentally, the main chains are in an extended conformation. The most plausible conformation in the extended form is shown in Figure 6a, which is based on conformational energy calculations ${ }^{15,16}$ as well as from the crystal structure of model compounds of $p$-phenylene polyesters such as phenyl benzoate. ${ }^{17}$ In this conformation, the phenyl ring and the adjacent ester groups are in a coplanar arrangement with the plane of successive phenyl groups twisted by about $60^{\circ}$. With this conformation in mind, it is difficult to imagine the packing of the aromatic main chains in a side-by-side fashion within a layer (which is tentatively illustrated in a previous $\operatorname{paper}^{10}$ ), since such a packing does not satisfy the space filling requirement in which molecules must assume a regular lateral packing with a short spacing of $3.85 \AA$ and simulatneously have a random displacement along the chain axis. Possibly in this case, the molecules may be packed in zig-zag sheets so as to produce the undulated layer as shown in Figure $6 \mathrm{~b}$, as has been proposed by Adam and Spiess. ${ }^{8}$ On the other hand, if a segregation of the aromatic main-chain and aliphatic side-chain domains is a main factor responsible for the formation of the layered structure, a side-by-side packing of the main chains within each layer (see Figure 6c) would be more preferable than the zig-zag packing. Considering that the $3.85 \AA$ spacing is as large as the van der Waals thickness (around $3.5 \AA$ ) of a phenyl ring, ${ }^{18}$ this type of packing can only be achieved for conformations in which the successive phenyl rings are in a coplanar arrangement. Conformational analysis is necessary for a more detailed illustration of this layered structure. 


\section{CONCLUSION}

Liquid crystalline phases were observed to be formed by $\mathrm{H}-\mathrm{Cn}$ polyesters where the carbon number in the alkyl side chains is 12 or longer. The liquid crystals have a characteristic layered structure which is not essentially changed with the variation of side-chain length. In this layered structure, the aromatic main chains in the extended form pack into layers with one-dimensionally positional order in the lateral direction and with the alkyl side chains in the disordered form occupying the space between the layers. From a linear relationship between the layer spacing and the side-chain length, the averaged densities were evaluated as $1.3 \mathrm{~g} \mathrm{ml}^{-1}$ and $0.9 \mathrm{~g} \mathrm{ml}^{-1}$ for the main-chain and side-chain domains, respectively. Such a layered structure can be illustrated to result from a kind of microphase separation of the aromatic and aliphatic components of the polymer, which is also expected from an unusual increase in the isotropization temperature of liquid crystals with an increase in the side-chain length.

\section{REFERENCES AND NOTES}

1. A. Cifferi, W. R. Krigbaum, and R. B. Meyer, "Polymer Liquid Crystals," Academic Press, New York, 1982.

2. M. Ballauff, Angew. Chem. Int. Ed. Engl., 28, 253
(1989).

3. M. Ballauff, Makromol. Chem., Rapid Commun., 7, 407 (1986).

4. M. Ballauff and G. F. Schmidt, Mol. Cryst. Liq. Cryst., 147, 163 (1987).

5. R. Stern, M. Ballauff, and G. Wegner, Makromol. Chem., Makromol. Symp., 23, 373 (1989).

6. J. M. Rodriguez-Parada, R. Duran, and G. Wegner, Macromolecules, 22, 2507 (1989).

7. M. Ebert, O. Herrmann-Schonherr, J. H. Wendorff, H. Ringsdorf, and P. Tschirner, Liq. Cryst., 7, 63 (1990).

8. A. Adam and H. W. Spiess, Makromol. Chem., Rapid Commun., 11, 249 (1990).

9. B. Stern, M. Ballauff, G. Lieser, and G. Wegner, Polymer, 32, 2097 (1991).

10. B. R. Harkness and J. Watanabe, Macromolecules, 24, 6759 (1991).

11. J. Watanabe, H. Ono, I. Uematsu, and A. Abe, Macromolecules, 18, 2141 (1985).

12. J. Watanabe, B. R. Harkness, and M. Sone, to be published; "The ${ }^{13} \mathrm{C}$ NMR for $\mathrm{H}-\mathrm{C} 18$ film indicates the coexistence of main-chain crystals and side-chain crystals that melt at the same temperature."

113. T. Yamagishi, T. Fukuda, T. Miyamoto, Y. Yakoh, Y. Takashina, and J. Watanabe, Liq. Cryst., 10, 467 (1991).

14. B. Ermann, J. J. Flory, and J. P. Hummel, Macromolecules, 13, 484 (1980).

15. J. P. Hummel and P. J. Flory, Macromolecules, 13. 479 (1980).

16. P. Coulter and A. H. Windle, Macromolecules, 22, 1129 (1989).

17. S. Harkema, R. J. Gaymans, G. J. van Hummel, and D. Zylberlicht, Acta Crystallogr., Sect. B, 35, 506 (1979).

18. J. M. Robertson, "Organic Crystals and Molecules," Cornell University Press, Ithaca, New York, 1953. 